DOI: 10.12731/2227-930X-2020-4-197-202

УДК 656.611.2

\title{
РАЗРАБОТКА СИСТЕМЫ МОДЕЛИРОВАНИЯ ДВИЖЕНИЯ СУДОВ
}

\section{Швецова А.Ф.}

Данный доклад посвящен рассмотрению прочесса моделирования движением судов. Подробно раскрывается значение термина судопоток в теории и практики судовождения. Особое внимание обращается на создание компьютерной программы, с помощью которой можно смоделировать поток на линейном фарватере.

Ключевые слова: зона навигационной безопасности; судовождение; судопоток; моделирование; система.

\section{DEVELOPMENT OF A VESSEL TRAFFIC SIMULATION SYSTEM}

\section{Shvetsova A.F.}

This report is devoted to the consideration of the process of modeling vessel traffic. The meaning of the term traffic flow in the theory and practice of navigation is revealed in detail. Particular attention is paid to the creation of a computer program with which it is possible to simulate the flow on a linear fairway.

Keywords: navigation security zone; navigation; traffic flow; modeling; system.

В наше время водные пути остаются основным средством осуществления мировой торговли: по ним перевозится около $80 \%$ грузов. До последнего времени объем мировой торговли и объем грузоперевозок морем увеличивались в среднем на $8 \%$ ежегодно. И в дальнейшем значение морских перевозок будет только 
возрастать. Кроме того, ежегодно сотни миллионов людей совершают морские путешествия на океанских лайнерах и местных судах, на моторных катерах и парусных яхтах. Сотни тысяч рыболовных судов круглый год находятся на промысле. С помощью плавучих и стационарных установок и платформ добывается нефть, газ и другие полезные ископаемые, в связи с чем создаются специализированные суда. Корабли военно-морских сил, пограничной и таможенной служб пользуются теми же морскими дорогами, что и другие суда. На морских просторах становится все теснее и теснее, происходит все больше столкновений на морских просторах и большее значение приобретает проблема управления движением судов.

\section{1. Понятие судопотока}

В определении «управление движением судов» ключевым является словосочетание «движение судов». Поэтому, чтобы формализовать термин «управление движением судов», необходимо определить процесс движения судов таким образом, чтобы его можно было бы идентифицировать как в качественных категориях, так и в количественных. Таким определением процесса движения судов может быть понятие «судопотока».

При этом судопоток обладает характеристиками (функциональными параметрами), которые имеют чёткое количественное определение, как то: плотность, интенсивность, средняя скорость, закон распределения, пространственное расположение. Следовательно, можно предположить, что управление движением судов может быть сведено к тому, чтобы путем внешних управляющих воздействий добиться установленных значений параметров функционирования судопотока. К примеру, если регулировать безопасные кильватерные расстояния между судами, то можно изменить плотность судопотока (движения судов), или, если установить системы разделения движения, то можно обеспечить необходимое пространственное распределение судопотоков в обозначенном районе. При этом процедуры управления движением судов име- 
ют финальную цель - повышение безопасности мореплавания и эффективности работы морского флота.

Судопоток - это совокупность или множество судов движущихся на определенном участке водного пути в одном направлении. Резкий и количественный рост состава и размеров судов мирового флота обозначил качественные и количественные изменения, повлиявшие на условия судоходства. В частности во многих районах, особенно в местах пересечения и слияния морских торговых путей: проливах, узкостях, подходных зонах, на фарватерах, каналах, сформировались постоянно функционирующие мощные потоки судов. В таких условиях особую остроту приобрели проблемы сопутствующие мореплаванию. В их числе высокая аварийность, а так же необходимость в решении задач связанных с оптимальным регулированием потоков судов. Таким образом, возникла целесообразность выделения теории судопотоков из общей теории транспортных потоков. Это обусловлено тем, что судопоток имеет слишком много характерных признаков, хотя и сохраняет главные свойства транспортного потока. Объектом изучения теории судопотоков являются характеристики движения судов на водных путях и возникающие при этом внутренние закономерности и их зависимость от внешних факторов. Изменения каких-либо параметров судопотоков путем внешнего воздействия, например, введения систем разделения движения преследуется при разработке практических мероприятий по регулированию движения судов. Однако, эти вопросы и составляют круг такого научного направления как теория управления судопотоками. Теория судопотоков, как отдельная область научных знаний в настоящее время находится в стадии формирования.

\section{2. Моделирование судопотока}

Продолжая изучение теории судопотоков, появилась идея создания моделирования судопотока, а так же системы моделирования процесса движения судов. Для этого был выбран метод изучения процесса движения судов на фарватере. Цель первого этапа модели- 
рования заключается в определении зависимостей количества (или вероятности) ситуаций опасного сближения от различных параметров, характеризующих навигационные условия плавания. Под ситуацией опасного сближения имеется в виду ситуация, когда расстояние между соседними судами уменьшается до такой величины, при которой возникает необходимость в маневрировании или для избежания столкновения, либо для выполнения обгона. Именно количество таких ситуаций в единицу времени определяет степень напряженности движения на водном пути. Моделируемая система может быть формализована следующим образом. На линейном фарватере длина (D) которого задается в промежутке от 500 до 500000 и ширина (W) в промежутке от 100 до 5000 метров, функционирует судопоток с односторонним движением, определяемый интенсивностью $(\lambda)$ от 1 до16 судов в час и средней скоростью (m). Моменты появления судов на входе в фарватер образуют случайный поток событий, интервалы между которыми $\Delta \mathrm{t}$ распределены по экспоненциальному закону с параметром $\lambda$. После того, как i-е судно появилось на входе в фарватер, ему присваиваются следующие параметры: номер судна, скорость фактическая $\mathrm{V}_{\text {now }}$, и скорость в результате задержки $\mathrm{V}_{\text {ini' }}$, длина $\mathrm{L}_{\mathrm{i}}$, ширина $\mathrm{Bi}$, зона навигационной безопасности (ЗНБ) прямо по носу судна $\mathrm{r}_{\mathrm{i}}$, (форму ЗНБ можно выбрать: круг или прямоугольник). Параметры V, L - случайные величины, закон распределения которых можно изменять. На рисунке 1 показаны суда в виде объектов с соответствующими ЗНБ, как они видны на экране монитора, а также расшифровка некоторых параметров. Ситуация опасного сближения идентифицировалась как касание ЗНБ двух близлежащих судов. В разработанной программе реализована возможность:

- выбора размеров фарватера;

- выбора параметров распределения скорости и длины судна и его координат;

- подсчета количества ситуаций опасного сближения;

- построения графиков зависимости количества опасных ситуаций от изменяемых параметров моделирования;

- ведения и просмотра журнала событий. 


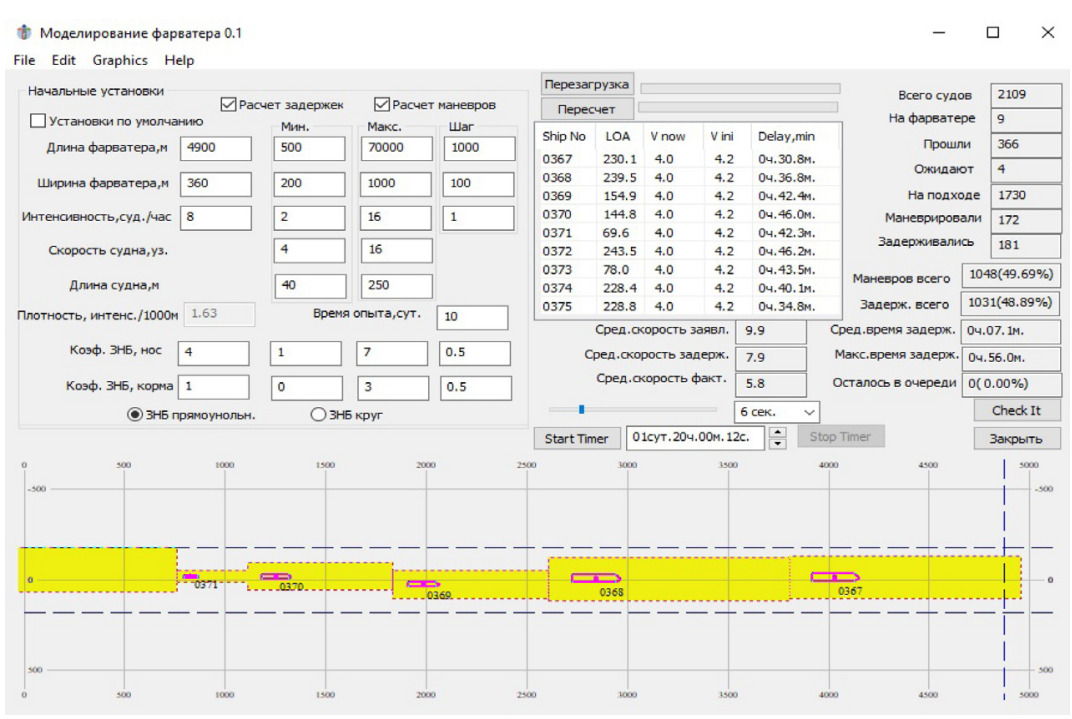

Рис. 1. Пример моделирования судопотока

В программе заложены широкие возможности для её развития и совершенствования путем добавления, например, блока маневрирования, блока взаимодействия судопотоков и другие. Представленная программа позволяет получать разнообразные результаты, однако на этом этапе основная цель заключалась в получении зависимостей количества ситуаций опасного сближения от различных параметров, характеризующих навигационные условия плавания.

\section{Благодарности}

Автор выражает признательность научному руководителю: Лентареву Александру Андреевичу, профессору кафедры судовождения МГУ им. адм. Г.И. Невельского, за помощь в создании данной работы.

Информация о конфликте интересов. Автор заявляет об отсутствии конфликта интересов.

Информация о спонсорстве. Исследование не имело финансовой поддержки. 


\section{Список литературы}

1. Лентарев А.А. Безопасность мореплавания - проблема системного анализа // Тез докл. Всесоюзной научной конференции «Безопасность на море». Николаев, 1992.

2. Баскин А.С., Пересыпкин В.И. Некоторые вопросы регламентации движения судов в портах и узкостях // Гидрография и гидрометеорология: Тр. ЛВВИМУ. 1972. Вып.1. С. 18-21.

\section{References}

1. Lentarev A.A. Safety of navigation - the problem of systems analysis: Abstracts of the report. All-Union scientific conference "Safety at sea". Nikolaev, 1992.

2. Baskin A.S., Peresypkin V.I. Some issues of regulation of the movement of ships in ports and narrowness. Hydrography and hydrometeorology: Tr. LVVIMU, 1972. Issue 1. P. 18-21.

\section{ДАННЫЕ ОБ АВТОРЕ}

Швецова Анастасия Федоровна, аспирант

ФБОУ ВПО «Морской государственный университет им. адм. Г.И. Невельского»

ул. Верхнепортовая, 50а, г. Владивосток, 690003, Российская Федерачия shvecos69@yandex.ru

\section{DATA ABOUT THE AUTHOR}

\section{Shvetsova Anastasia Fedorovna, Graduate Student}

Maritime State University G.I. Nevelskogo

50A, Verkhneportovaya Str., Vladivostok, 690003, Russian Federation

shvecos69@yandex.ru

ORCID: 0000-0001-9704-2095 